\title{
MOTIVAÇÃO DOS MESTRANDOS EM CIÊNCIAS CONTÁBEIS PARA A REALIZAÇÃO DO DOUTORADO: UMA ANÁLISE A PARTIR DA ESCALA DE MOTIVAÇÃO ACADÊMICA (EMA)
}

\section{MOTIVATION OF MASTERS STUDENTS IN ACCOUNTING FOR THE REALIZATION OF DOCTORATE: AN ANALYSIS OF THE ACADEMIC MOTIVATION SCALE (AMS)}

0 artigo foi aprovado e apresentado no XI Congresso ANPCONT, realizado de 03 a 06 de junho de 2017, em Belo Horizonte (MG).

\section{RESUMO}

O objetivo do estudo é verificar o nível motivacional dos mestrandos em Ciências Contábeis com relação ao ingresso em um programa de doutorado. Assim, essa pesquisa, que é classificada como descritiva e quantitativa, se propõe a responder a seguinte questão de pesquisa: Qual o nível motivacional dos mestrandos dos Cursos de Ciências Contábeis que os leva a ingressarem em um programa de doutorado? A coleta de dados foi realizada com a aplicação de questionários aos mestrandos dos cursos de pós-graduação stricto sensu em Ciências Contábeis no Brasil, e contou com a participação de 209 respondentes. O questionário utilizado na pesquisa foi estruturado com base na Escala de Motivação Acadêmica (EMA), que faz uso de conceitos da Teoria da Autodeterminação. Além da descrição dos dados, foram utilizados os seguintes procedimentos estatísticos para o tratamento dos dados: análise de correlação; cálculo do Índice de Autodeterminação da Motivação (IAM), desenvolvido por Sobral (2008); teste Shapiro-Wilk; e coeficiente de correlação Spearman. A partir dos achados, verificou-se que, em geral, os mestrandos em Ciências Contábeis apresentam satisfação, prazer e interesse em buscar novos conhecimentos, estando motivados intrinsecamente em ingressar em um programa de doutorado e manter contato com o meio acadêmico. Os respondentes consideram que o título de doutor representa um diferencial na carreira acadêmica e profissional, refletindo também em benefícios financeiros.

Palavras chave: Motivação; Mestrandos; Escala de Motivação Acadêmica; Teoria da Autodeterminação.

\section{ABSTRACT}

This study aims to verify the motivational level of masters students in accounting in relation to enter to a doctorate program. So, this research, which is classified as a descriptive and quantitative approach, and proposes to answer the following research question: What is the motivational level of the masters students in accounting that leads them to enter a doctorate program. The data collection was carried out with the application of questionnaires to the masters students of the stricto sensu postgraduate courses in accounting in Brazil, and was attended by 209 respondents. The questionnaire used in the research was structured based on the Academic Motivation Scale (AMS), which makes use of concepts of the Self-determination Theory. In addition to describing the data, the following statistical tools were used for the treatment of the data: correlation analysis; calculation of index of Self-determination of Motivation (IAM), developed by Sobral (2008); Shapiro-Wilk test; and Spearman correlation coefficient. From the findings, it was verified that, in general, the masters students in accounting presented satisfaction, pleasure and interest in seeking new knowledge, being intrinsically motivated to enter a doctorate program and maintain contact with the academic environment. Respondents consider that the doctorate degree represents a differential in the academic and professional career, also reflecting financial benefits.

Keywords: Motivation; Masters; Academic Motivation Scale; Self-determination Theory.

\author{
Caio Cesar Violin de Alcantara \\ Mestre em Ciências Contábeis pela \\ Universidade Estadual de Maringá \\ (UEM). Graduado em Ciências Contábeis \\ pela Universidade Estadual de Maringá \\ (UEM). Docente do curso de Graduação \\ em Ciências Contábeis na Faculdade \\ Santa Maria da Glória (SMG). Contato: \\ Rua Marechal Deodoro, 1278, Apto. \\ 101, Maringá, PR, CEP: 87.030-020. \\ E-mail: caiocvalcantara@gmail. \\ com / caioalcantara_94@hotmail.com
}

\section{Matheus Henrique Delmonaco Mestre em Contabilidade, linha de pesquisa - Contabilidade para Usuários Externos, área de concentração Controladoria, pela Universidade Estadual de Maringá (UEM, 2018). Graduado em Ciências Contábeis pela Universidade Estadual de Maringá (UEM). Contato: Av. Colombo, 5790, Jd. Universitário, Maringá PR, CEP: 88.020-900 E-mail: mathenr10@ gmail.com}

\section{Reinaldo Rodrigues Camacho} Doutor em Controladoria e Contabilidade pela FEA/USP. Professor Associado do Departamento de Ciências Contábeis da Universidade Estadual de Maringá (UEM). Endereço: Rua Rui Barbosa, 625 AP 1001, CEP 87.020-090 Maringá, PR. E-mail: rrcamacho@uem.br

\section{Katia Abbas}

Doutora e Mestre em Engenharia de Produção pela Universidade Federal de Santa Catarina (UFSC). Graduada em Ciências Contábeis pela Universidade Estadual de Maringá (UEM). Docente dos cursos de Graduação e Pós-Graduação em Ciências Contábeis na Universidade Estadual de Maringá (UEM). Contato: Av. Colombo, 5790, Jd. Universitário, Maringá, PR, CEP: 88.020-900. E-mail: kabbas@ uem.br / katia_abbas@yahoo.com.br 


\section{INTRODUÇÃO}

A escolha por prosseguir na educação pode partir de vários motivos, como posição, empregabilidade, satisfação pessoal, status social, reconhecimento acadêmico ou profissional, acréscimo salarial, entre outros fatores. Entender a questão de como a educação contribui para o sucesso profissional e social é pertinente por razões práticas e teóricas. Segundo Lima (1980), a melhoria do nível de especialização dos trabalhadores, o aumento das habilidades, maior grau de educação, de proporção crescente da população e maior acumulação de conhecimentos, são reconhecidos como fatores importantes para o crescimento econômico.

Os retornos individuais pela educação mudam ao longo do tempo, envolvendo interação entre a demanda e a oferta de trabalhadores por tipo de qualificação, sendo assim, o indivíduo que aplica uma renda em educação e formação deseja um aumento de ganhos no futuro (Blundell, Dearden, Meghir \& Sianesi, 1999).

A Teoria da Autodeterminação está posicionada em questões relacionadas à autorregulação, uma vez que reconhece as tendências e as integrações dos seres humanos, aborda os fatores sociais e postula a existência de três necessidades psicológicas básicas universais (autonomia, competência e conectividade) (Deci, Ryan, Vallerand \& Pelletier, 1991). Segundo Biondi et al. (2015) a Teoria da Autodeterminação é relevante para todos os níveis de educação, pois a motivação é a energia primária das pulsões para aprendizagem. Diante disso, mostra-se apropriada a utilização dessa teoria para o presente estudo, tendo em vista a sua grande aplicabilidade (Durso, Cunha, Neves \& Teixeira, 2016).

A partir da Teoria da Autodeterminação, Vallerand et al. (1992) desenvolveram a Escala de Motivação Acadêmica (EMA), que desde então tem sido amplamente utilizada em estudos na área de Educação (Durso et al., 2016). O primeiro estudo em âmbito nacional foi o de Sobral (2003), sendo o primeiro autor a traduzir o instrumento de pesquisa para o português.

A EMA é constituída de 28 itens, subdivididos em 7 subescalas, que incluem tipos de motivação intrínseca, motivação extrínseca e desmotivação ou ausência de motivação. Diante da aplicabilidade desse instrumento em estudos recentes, tais como os de Leal Miranda e Carmo (2013), Lopes, Pinheiro, Silva e Abreu (2015) e Durso et al. (2016), pesquisas novas e mais aprofundadas se fazem necessárias (Leal, Miranda \& Carmo, 2013).

Frente ao exposto, este estudo se propõe a responder a seguinte questão: Qual o nível motivacional dos mestrandos dos Cursos de Ciências Contábeis que os leva a ingressarem em um programa de Doutorado? Para responder ao problema proposto, o objetivo do estudo é verificar o nível motivacional dos mestrandos em Ciências Contábeis em relação a ingressarem em um programa de doutorado.

Em 1970 foi criado o primeiro curso de pós-graduação stricto sensu em Ciências Contábeis no Brasil, na Faculdade de Economia e Administração da Universidade de São Paulo (FEA/USP). Desde então, vê-se um crescimento no número de cursos de pós-graduação stricto sensu na área no país, embora durante cerca de trinta anos foram ofertados apenas três cursos em todo o Brasil. Percebe-se que esse crescimento ocorreu, em grande parte, a partir dos anos 2000. Com esta expansão dos cursos de Pós-Graduação em Ciências Contábeis, a demanda por formação de qualidade no corpo docente também aumentou.

Portanto, justifica-se a escolha pela aplicação do estudo com os mestrandos em Ciências Contábeis devido ao recente crescimento no número de programas de pós-graduação na área no Brasil, bem como pelo fato de que vagas para cargos de professores nas universidades públicas, tanto estaduais quanto federais, exige, na maioria das vezes, o título de doutor. A opção pelos programas stricto sensu apoia-se no fato de que são esses os cursos voltados à formação na área acadêmica e, além disso, a realização de pesquisas com mestrandos se mostram oportunas, tendo em vista que o número de respondentes é satisfatório.

\section{REFERENCIAL TEÓRICO}

\subsection{Pós-graduação stricto sensu em Ciências Contábeis no Brasil}

A pós-graduação no Brasil foi regulamentada pelo Parecer n 977/65 do Conselho de Educação Superior (CESu). Além de definir as características e conceitos dos cursos de mestrado e doutorado, e estruturar a pós-graduação brasileira nos moldes do sistema norte-americano, este parecer trata da distinção entre a pós-graduação stricto sensu e lato sensu. O parecer define a pós-graduação lato sensu como todo e qualquer curso que se segue à graduação, tais como os de especialização e aperfeiçoamento, ou seja, os que são mais direcionados à atualização dos alunos graduados. Os cursos stricto sensu são aqueles com objetivos mais amplos e aprofundados de formação científica e profissional, que se sobrepõem à graduação, sendo parte integrante do complexo universitário (Brasil, 1965).

A Tabela 1 apresenta os cursos de mestrado acadêmico em Ciências Contábeis no Brasil que são reconhecidos e recomendados pela Capes, segundo a avaliação mais recente (Capes, 2016). Atualmente existem 26 cursos de mestrado acadêmico. 
Tabela 1: Cursos de mestrado acadêmico em Ciências Contábeis no Brasil reconhecidos pela CAPES.

\begin{tabular}{|c|c|c|c|}
\hline NOME DA INSTITUIÇÃO DE ENSINO & SIGLA & ESTADO & ANO* \\
\hline CENTRO UNIVERSITÁRIO FECAP & UNIFECAP & SP & 1999 \\
\hline FUCAPE PESQUISA ENSINO E PARTICIPAÇÕES LIMITADA & FUCAPE-MA & MA & 2016 \\
\hline FUND. INST. CAPIXABA DE PESQ. EM CONT.ECON.E FINANÇAS & FUCAPE & ES & 2000 \\
\hline PONTIFÍCIA UNIVERSIDADE CATÓLICA DE SÃO PAULO & $\mathrm{PUC} / \mathrm{SP}$ & SP & 1978 \\
\hline UNIVERSIDADE COMUNITÁRIA DA REGIÃO DE CHAPECÓ & UNOCHAPECÓ & SC & 2015 \\
\hline UNIVERSIDADE DE BRASÍLIA & UNB & $\mathrm{DF}$ & 2015 \\
\hline UNIVERSIDADE DE SÃO PAULO & USP & SP & 1970 \\
\hline UNIVERSIDADE DE SÃO PAULO/ RIBEIRÃO PRETO & $\mathrm{USP} / \mathrm{RP}$ & SP & 2005 \\
\hline UNIVERSIDADE DO ESTADO DO RIO DE JANEIRO & UERJ & RJ & 2006 \\
\hline UNIVERSIDADE DO VALE DO RIO DOS SINOS & UNISINOS & RS & 1998 \\
\hline UNIVERSIDADE ESTADUAL DE MARINGÁ & UEM & PR & 2014 \\
\hline UNIVERSIDADE ESTADUAL DO OESTE DO PARANÁ & UNIOESTE & PR & 2015 \\
\hline UNIVERSIDADE FEDERAL DA BAHIA & UFBA & BA & 2006 \\
\hline UNIVERSIDADE FEDERAL DA PARAÍBA/JOÃO PESSOA & UFPB/J.P. & $\mathrm{PB}$ & 2015 \\
\hline UNIVERSIDADE FEDERAL DE GOIÁS & UFG & GO & 2016 \\
\hline UNIVERSIDADE FEDERAL DE MINAS GERAIS & UFMG & MG & 2006 \\
\hline UNIVERSIDADE FEDERAL DE PERNAMBUCO & UFPE & $\mathrm{PE}$ & 2007 \\
\hline UNIVERSIDADE FEDERAL DE SANTA CATARINA & UFSC & SC & 2003 \\
\hline UNIVERSIDADE FEDERAL DE UBERLÂNDIA & UFU & MG & 2013 \\
\hline UNIVERSIDADE FEDERAL DO ESPÍRITO SANTO & UFES & ES & 2010 \\
\hline UNIVERSIDADE FEDERAL DO PARANÁ & UFPR & PR & 2004 \\
\hline UNIVERSIDADE FEDERAL DO RIO DE JANEIRO & UFRJ & RJ & 1999 \\
\hline UNIVERSIDADE FEDERAL DO RIO GRANDE DO NORTE & UFRN & $\mathrm{RN}$ & 2015 \\
\hline UNIVERSIDADE FEDERAL DO RIO GRANDE DO SUL & UFRGS & RS & 2016 \\
\hline UNIVERSIDADE FEDERAL RURAL DE PERNAMBUCO & UFRPE & PE & 2015 \\
\hline UNIVERSIDADE REGIONAL DE BLUMENAU & FURB & SC & 2006 \\
\hline
\end{tabular}

* Ano de autorização de funcionamento.

Fonte: Adaptado de Capes (2016).

A CAPES foi reconhecida como órgão responsável pela elaboração do Plano Nacional de Pós-Graduação Stricto Sensu em 1981, e desde então avalia os programas de pós-graduação no país. A avaliação é realizada para programas já reconhecidos pelo órgão, que passam por um processo de avaliação trienal, e também para novos cursos aspirantes à recomendação (Capes, 2016).

A Capes adotou em 1998 o padrão internacional para avaliação de desempenho dos programas de mestrado, utilizando a escala de notas de 1 a 7, sendo considerada a nota 3 como mínima para validação nacional dos diplomas emitidos pelos programas. Somente os cursos com nota igual ou superior a 3 são recomendados ou renovados pelo Conselho Nacional de Educação - CNE/MEC (Capes, 2016).

Diante da ampla utilização da Teoria da Autodeterminação em estudos ligados à motivação de estudantes e também da aplicação da Escala de Motivação Acadêmica (EMA), é importante verificar a motivação desses mestrandos em Ciências Contábeis em relação à realização de um curso de doutorado no futuro. 


\subsection{Teoria da Autodeterminação}

Por volta de 1981, Richard M. Ryan e Edward L. Deci, na época professores do Departamento de Clínica e Ciência Social do Departamento de Psicologia da Universidade de Rochester nos Estados Unidos, desenvolveram a Teoria da Autodeterminação, contrapondo as ideias de outras teorias que afirmavam que todo comportamento seria função da satisfação de necessidades fisiológicas. Os referidos professores afirmaram que, para estarem intrinsecamente motivadas, as pessoas necessitam se sentirem competentes e autodeterminadas (Oliveira, Theóphilo, Batista \& Soares, 2010).

A Teoria da Autodeterminação vem sendo utilizada em estudos que procuram entender a motivação das pessoas na educação, nos negócios ou na saúde (Biondi et al., 2015). De acordo com Deci e Ryan (2000), a autodeterminação parte da autonomia (origem interna do indivíduo, livre arbítrio na escolha de objetivos), competência (necessidade de se sentir eficaz nas ações que busca e executa) e conectividade (desejo de se sentir conectado com outros, pertencer e ser valorizado por uma comunidade), promovendo ação intencional ou motivada. Estar motivado significa ser motivado por alguma coisa, sendo a motivação dificilmente um fenômeno único.

Na Teoria da Autodeterminação, segundo Sobral (2003), as motivações diferem e são determinadas e orientadas pelo contexto que dão assistência às necessidades psicológicas. Deci e Ryan (2008) diferenciam a motivação em diversos níveis (subgrupos), com o objetivo de verificar qual tipo ou qualidade de uma motivação específica é mais importante que os demais para predizer ou influenciar determinados comportamentos.

Dois tipos básicos de motivação são caracterizados: motivação intrínseca e motivação extrínseca. Os comportamentos intrinsecamente motivados (motivação intrínseca) estão relacionados ao bem próprio, para o prazer e satisfação derivada de seu desempenho. Um exemplo de motivação intrínseca ocorre quando o estudante vai à aula porque acha interessante e se satisfaz aprendendo mais sobre certas matérias. Já na motivação extrínseca os comportamentos não são realizados fora do interesse, mas porque se acredita ser fundamental para alguma consequência. A motivação extrínseca assume diferentes formas, que se distinguem pelo grau de internalização e integração de valores e regulação de condutas, refletindo diferentes graus de autonomia (Deci \& Ryan, 1985; Deci et al., 1991; Deci \& Ryan, 2000). O Continuum de autodeterminação (figura 1), apresentado por Gagné e Deci (2005), retrata os tipos de motivação e suas respectivas variações.

Figura 1: Continuum de autodeterminação.

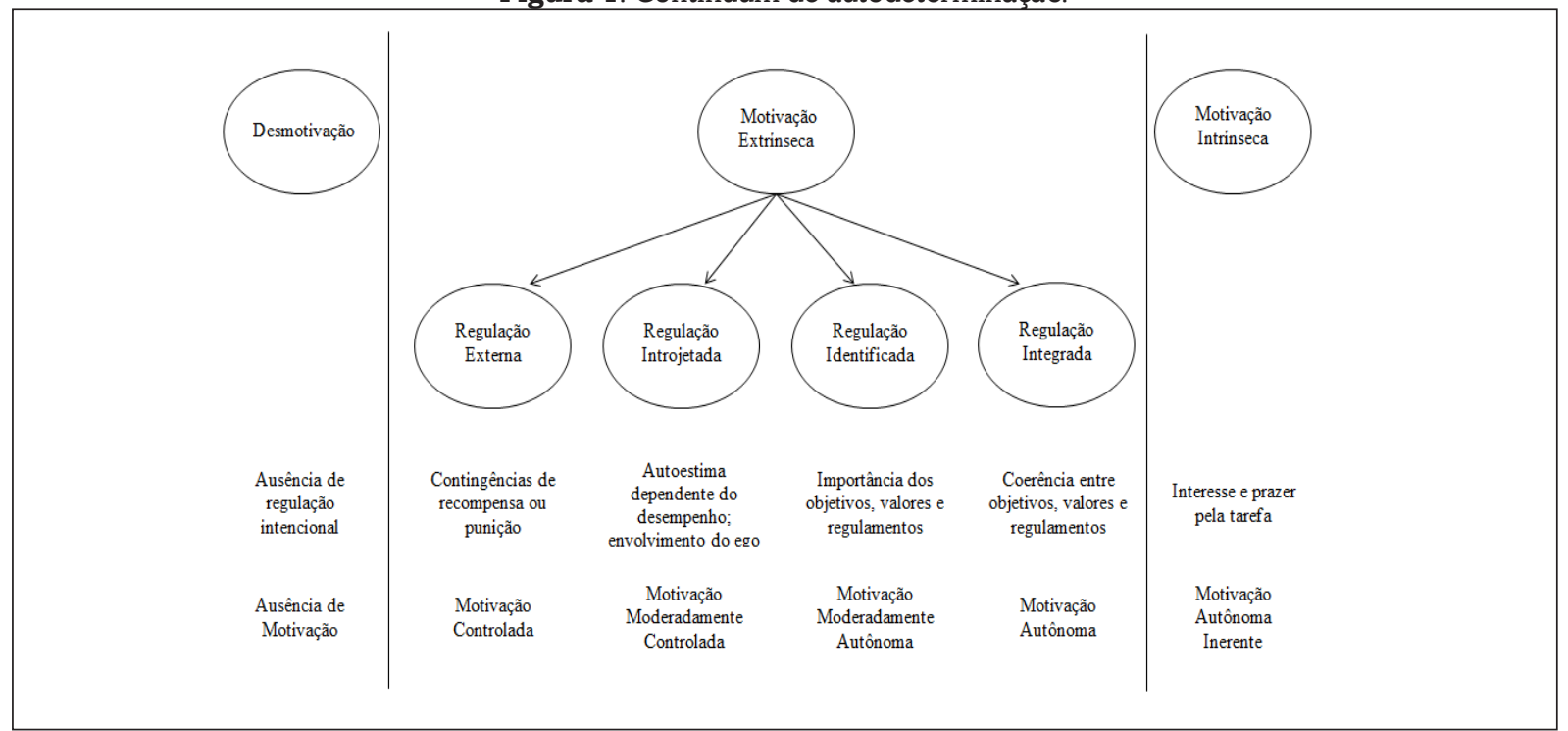

Fonte: Adaptado de Gagné e Deci (2005, p. 336).

Segundo Guimarães, Bzuneck e Sanches (2002) existem evidências de que a motivação intrínseca facilita a aprendizagem e o desempenho. $\mathrm{O}$ discente busca se envolver em atividades que ofereçam oportunidades para o aprimoramento de habilidades e novos conhecimentos com intenção de aplicá-los futuramente. A motivação extrínseca refere-se à motivação para trabalhar em resposta a algo externo, como a obtenção de recompensas materiais ou sociais, de reconhecimento ou objetivando atender aos comandos de terceiros. Uma motivação autônoma relaciona-se com mais qualidade no aprendizado, maior persistência e melhor ajuste psicológico dos aprendizes, do ensino primário ao ensino superior (Sobral, 2003). A falta de intencionalidade e causalidade do indivíduo é devido à desmotivação. De acordo com Deci, Ryan e Kuhl (1997), a Teoria da Autodeterminação é uma abordagem da motivação e personalidade humana, que usa métodos empíricos tradicionais, destacando a importância de expandir os recursos internos dos seres humanos para o desenvolvimento da personalidade e autorregulação comportamental. 


\subsection{Escala de Motivação Acadêmica}

Desenvolvida por Vallerand et al. (1992), com base nos conceitos da Teoria da Autodeterminação, a EMA foi traduzida para o português por Sobral (2003), que buscou analisar as características da motivação de estudantes de medicina, e desde então vem sendo utilizada por estudos nacionais relacionados à motivação (Guimarães \& Bzuneck, 2008; Lopes et al., 2015; Durso et al, 2016).

A escala reúne 28 itens, distribuídos em 7 subescalas, sendo: 3 escalas correspondentes a tipos de motivação intrínseca, 3 escalas relacionadas a tipos de motivação extrínseca, e uma que retrata a desmotivação (Sobral, 2003; Sobral, 2008), conforme destacado no quadro 1.

Quadro 1: Níveis de motivação da Escala EMA.

\begin{tabular}{|l|l|}
\hline Motivação Intrínseca para Saber & $\begin{array}{l}\text { Fazer algo pelo prazer e satisfação que decorrem de aprender, explorar ou } \\
\text { entender. }\end{array}$ \\
Motivação Intrínseca para Realização & $\begin{array}{l}\text { Fazer algo pelo prazer e satisfação que decorrem da busca de realização ou } \\
\text { criação de coisas. } \\
\text { Fotivação Intrínseca para Vivenciar Estímulos }\end{array}$ \\
$\begin{array}{ll}\text { Motivação Extrínseca por Identificação a fim de experimentar sensações estimulantes, de natureza sensorial } \\
\text { ou estética. }\end{array}$ \\
Motivação Extrínseca Regulada por Introjeção & $\begin{array}{l}\text { Fazer algo porque se decidiu fazê-lo. } \\
\text { Fotivação Extrínseca por Controle Externo porque se pressiona a si próprio a fazê-lo. }\end{array}$ \\
Desmotivação & Fazer algo porque se sente pressionado por outros a fazê-lo. \\
\end{tabular}

Fonte: Sobral (2003, 2008).

Justifica-se a utilização da Escala de Motivação Acadêmica (EMA) em razão da grande aplicabilidade que esse instrumento vem apresentando em pesquisas relacionadas à motivação de acadêmicos e com uma diversidade de públicos, apresentando eficiência na mensuração dos níveis motivacionais (Durso et al., 2016), o que desperta o interesse em realizar a aplicação com alunos de pós-graduação da área de contabilidade. Estudos anteriores realizados com a utilização da EMA, em âmbito nacional e internacional, retratam a consistência e validade do instrumento de pesquisa, como evidenciam Guimarães e Bzuneck (2008) e Durso et al. (2016).

Vallerand et al. (1992) desenvolveram a EMA e, após ter sido traduzida para o português por Sobral (2003), vários estudos foram realizados com sua utilização em âmbito nacional. Guimarães e Bzuneck (2008) buscaram levantar as propriedades psicométricas da versão brasileira da Escala de Motivação Acadêmica de Sobral (2003) com um grupo de universitários da região do norte do estado do Paraná, identificando boa consistência interna, e sendo possível a confirmação do modelo teórico. Martins e Monte (2009) procuraram traçar o perfil do mestre egresso, e verificaram, com base na amostra dos autores, que há influência positiva na obtenção do título de mestre, principalmente nos fatores empregabilidade e renda.

Oliveira et al. (2010) realizaram um estudo com o propósito de identificar, com base na Teoria da Autodeterminação, o nível de motivação de acadêmicos do Curso de Ciências Contábeis da Universidade Estadual de Montes Claros (UNIMONTES). Os resultados revelaram altos níveis de motivação dos alunos, porém, verificou-se um menor nível de motivação dos alunos veteranos e um menor nível do tipo de motivação ligada ao prazer com a universidade.

Leal, Miranda e Carmo (2013) investigaram a motivação dos estudantes de Ciências Contábeis de uma universidade pública brasileira, à luz da Teoria da Autodeterminação. Os autores identificaram motivações bem diversificadas para a aprendizagem entre os 259 universitários estudados. As análises revelaram estudantes preocupados em aprimorar o conhecimento ou em atingir uma fundamentação adequada para desempenhar a profissão no futuro, mas também houve estudantes que manifestaram preocupação apenas com a obtenção do diploma ou com interesse em comparecer às aulas apenas para garantir frequência.

$\mathrm{Na}$ intenção de observar se existem diferenças significativas nos níveis de motivação entre alunos de Instituições de Ensino Superior públicas e privadas nos cursos de Ciências Contábeis, Lopes et al. (2015) realizaram um estudo com a utilização da escala EMA no estado da Bahia. A partir dos achados, os autores constataram que não há diferenças estatisticamente significativas entre a motivação dos alunos de IES públicas e privadas.

Apesar disso, algumas diferenças foram encontradas no estudo de Oliveira et al. (2010), quando analisados isoladamente gênero, idade e estágio do curso. Verificou-se que as mulheres possuem, em média, mais motivação do que os 
homens, e que os alunos iniciantes são mais motivados por introjeção e menos desmotivados do que aqueles que estão em fase de conclusão.

Durso et al. (2016) analisaram, também pela ótica da Teoria da Autodeterminação, o nível motivacional dos estudantes de Ciências Contábeis e Ciências Econômicas com relação à busca por uma pós-graduação stricto sensu. Os autores partiram do pressuposto de que a escassez de profissionais na área de Ciências Contábeis com o título de mestre, quando comparado com o número de mestres em Ciências Econômicas, encontrava-se no fato de os discentes de graduação em Ciências Contábeis possuírem baixa motivação intrínseca para a continuidade dos estudos após o bacharelado. Porém, após as análises, foi possível perceber que o nível motivacional dos estudantes de Ciências Contábeis não é estatisticamente diferente do nível motivacional dos discentes de Ciências Econômicas. Assim sendo, o principal resultado desta pesquisa sugere que a existência de menos discentes de Ciências Contábeis que ingressam em um mestrado acadêmico se deve ao fato de possuírem um perfil mais voltado para o mercado de trabalho.

Diante do exposto, torna-se relevante investigar o nível motivacional dos mestrandos em Ciências Contábeis com relação ao ingresso em um programa de doutorado, tendo em vista o recente crescimento no número de programas de pós-graduação nacionais na área voltados à formação acadêmica.

\section{PROCEDIMENTOS METODOLÓGICOS}

Com relação aos objetivos, este estudo se enquadra como descritivo, que, de acordo com Silva (2010), tem como objetivo principal descrever as características de determinada população ou fenômeno, estabelecendo relação entre variáveis. Quanto à estratégia de pesquisa, o estudo empregou a pesquisa de levantamento, utilizando o questionário como instrumento de coleta de dados. Por se tratar de uma pesquisa que utiliza métodos estatísticos, caracteriza-se como quantitativa. Segundo Richardson (2012), o método quantitativo se caracteriza pelo emprego da quantificação, tanto nas modalidades de coleta de informações, quanto no tratamento delas por meio de técnicas estatísticas.

Os dados foram coletados por meio da aplicação de questionários aos mestrandos de programas de mestrado acadêmico em Ciências Contábeis no Brasil, envolvendo instituições públicas e privadas. Para tanto, foi realizado em agosto de 2016 um levantamento dos cursos de mestrado acadêmico (stricto sensu) que são reconhecidos pela Capes, obtendo um total de 26 cursos ofertados em todo o Brasil (tabela 1). Após o levantamento, os questionários foram enviados por meio do endereço eletrônico (e-mail) dos programas de mestrado, solicitando a divulgação do link de pesquisa aos alunos.

O questionário foi dividido em duas partes, sendo a primeira composta por sete questões relacionadas ao perfil demográfico dos respondentes: (1) gênero; (2) idade; (3) estado civil; (4) instituição de ensino; (5) se é contemplado com bolsa de estudos; (6) período em que se encontra no mestrado; e (7) se possui vínculo empregatício. Para esta última, caso a resposta fosse positiva, os respondentes também assinalaram a sua respectiva faixa salarial.

A segunda parte do questionário, composta pela Escala de Motivação Acadêmica (EMA), foi adaptada do estudo de Sobral (2003). Esta seção do questionário lista 28 itens que podem representar razões para o mestrando ingressar em um doutorado na área de contabilidade (listados na tabela 3), onde os respondentes deveriam assinalar o nível de concordância/discordância, variando de 1 (discordo totalmente) a 10 (concordo totalmente). O agrupamento para as afirmativas do questionário foi realizado com base nos trabalhos de Vallerand, Blais, Brière e Pelletier (1989), Vallerand et al. (1992), Sobral (2003), Sobral (2008) e Durso et al. (2016).

Além da descrição dos itens que compõem a Escala EMA, para o tratamento e análise dos dados são utilizadas algumas ferramentas estatísticas, por meio do software Stata 13. Primeiramente, são realizados os coeficientes de correlação, para verificar a associação entre pares de variáveis. Em seguida, é calculado o Índice de Autodeterminação da Motivação, desenvolvido por Sobral (2008), por meio da equação 1:

$$
(I A M=((2(a+b+c) / 3+d)-((e+f) / 2+2 g)),
$$

As letras referem-se aos níveis motivacionais apontados no Quadro 1. O IAM pode variar de -108 a +108 , tendo em vista que para cada letra da sua fórmula existem quatro afirmativas possíveis, cujo valor pode variar de 1 a 10 .

Para identificar os fatores que mais estão correlacionados ao nível de motivação dos mestrandos, é realizada a análise de correlação. Além disso, é aplicado o teste Shapiro-Wilk, com o intuito de verificar se as variáveis dos tipos de motivação apresentam normalidade. As variáveis utilizadas para explicar o IAM (variável dependente) nas regressões foram obtidas a partir do perfil demográfico do instrumento de coleta de dados do estudo. Os achados obtidos foram utilizados na análise dos resultados para as conclusões da pesquisa e também para comparação com os estudos citados no referencial teórico.

\section{ANÁLISE E INTERPRETAÇÃO DOS RESULTADOS}

Foram obtidas respostas de mestrandos de 20 programas, dos 26 listados na tabela 1, obtendo um total de 209 observações, conforme evidenciado na tabela 2. Destas, cerca de $46 \%$ são de programas de mestrado da região Sul do 
Brasil, $40 \%$ da região Sudeste, $11 \%$ da região Nordeste e 3\% da região Centro Oeste. O Paraná obteve a maior representatividade entre os Estados, com quase $26 \%$ do total das observações.

Tabela 2: Número de respondentes por Instituição de Ensino.

\begin{tabular}{|c|c|c|}
\hline NOME DA INSTITUIÇÃO DE ENSINO & ESTADO & $\mathbf{N}^{\circ}$ DE RESPOSTAS \\
\hline UNIVERSIDADE ESTADUAL DE MARINGÁ & PR & 23 \\
\hline CENTRO UNIVERSITÁRIO FECAP & SP & 18 \\
\hline UNIVERSIDADE FEDERAL DO PARANÁ & PR & 16 \\
\hline UNIVERSIDADE DO VALE DO RIO DOS SINOS & $\mathrm{RS}$ & 15 \\
\hline UNIVERSIDADE ESTADUAL DO OESTE DO PARANÁ & PR & 15 \\
\hline UNIVERSIDADE FEDERAL DO ESPÍRITO SANTO & ES & 12 \\
\hline UNIVERSIDADE REGIONAL DE BLUMENAU & SC & 12 \\
\hline UNIVERSIDADE FEDERAL DE MINAS GERAIS & MG & 11 \\
\hline UNIVERSIDADE FEDERAL DE SANTA CATARINA & SC & 11 \\
\hline UNIVERSIDADE FEDERAL DE UBERLÂNDIA & MG & 11 \\
\hline UNIVERSIDADE DO ESTADO DO RIO DE JANEIRO & $\mathrm{RJ}$ & 10 \\
\hline UNIVERSIDADE FEDERAL DO RIO DE JANEIRO & $\mathrm{RJ}$ & 10 \\
\hline UNIVERSIDADE FEDERAL DE PERNAMBUCO & PE & 9 \\
\hline UNIVERSIDADE DE SÃO PAULO & SP & 8 \\
\hline UNIVERSIDADE FEDERAL DE GOIÁS & GO & 7 \\
\hline UNIVERSIDADE FEDERAL DA BAHIA & BA & 6 \\
\hline UNIVERSIDADE FEDERAL DO RIO GRANDE DO NORTE & RN & 6 \\
\hline UNIVERSIDADE DE SÃO PAULO (RIBEIRÃO PRETO) & SP & 4 \\
\hline UNIVERSIDADE FEDERAL DO RIO GRANDE DO SUL & RS & 4 \\
\hline UNIVERSIDADE FEDERAL DA PARAÍBA/JOÃO PESSOA & PB & 1 \\
\hline \multicolumn{2}{|l|}{ TOTAL } & 209 \\
\hline
\end{tabular}

Fonte: Dados da pesquisa.

Os dados demográficos levantados na amostra pesquisada apontam para uma maior representatividade feminina, correspondendo a 51,7\% dos mestrandos que participaram da pesquisa. Os respondentes têm entre 22 e 58 anos, sendo que a maioria tem entre 22 e 30 anos (cerca de $60 \%$ ). Quanto ao estado civil, $54,5 \%$ dos mestrandos que fizeram parte da amostra são solteiros, $42,1 \%$ casados e 3,3\% divorciados.

Dentre o montante de respondentes, 88 disseram ser bolsistas no programa de mestrado, o que corresponde a $42,1 \%$. Com relação ao período (estágio) em que se encontram no mestrado, 57,4\% dos alunos que fazem parte da amostra estão somente na fase de dissertação, 28,7\% estão realizando os créditos (disciplinas) e a dissertação, e outros $13,9 \%$ se encontram realizando apenas os créditos.

O questionário também investiga se os mestrandos participantes da pesquisa possuem vínculo empregatício e, se sim, eles deveriam assinalar a respectiva faixa salarial. Destaca-se que mais da metade dos respondentes ( $53,1 \%)$ possui vínculo de trabalho, ou seja, 111 mestrandos, sendo que 52 deles $(46,8 \%)$ recebem mais de 5 salários mínimos, e outros $41,4 \%$ ganham entre 3 e 5 salários mínimos. A tabela 2 apresenta o percentual de distribuição das respostas para cada um dos 28 itens da escala.

O item 5 retrata a opinião dos respondentes quanto aos benefícios futuros e o que o doutorado pode proporcionar, pois a grande maioria dos mestrandos que fizeram parte da amostra consideram relevante a realização do doutorado, não sendo considerada uma perda de tempo. Os mestrandos, apesar de considerarem importante a realização do doutorado, por outro lado, tem dúvidas se a realização do mesmo oferece de fato um benefício real, o que é retratado no item 11. As respostas para este item foram mais dispersas, sendo que a média das respostas é de 4,65 e a mediana 4.

Outro ponto relevante está no contato com o meio acadêmico, que fazem parte da motivação extrínseca regulada por identificação. O item 4 aborda explicitamente esse aspecto, e cerca de $71 \%$ dos alunos assinalaram as alternativas 
de maior concordância (8, 9 e 10), o que revela que a possibilidade de realização de um doutorado está atrelada também à manutenção do contato com o meio acadêmico. De maneira semelhante, o item 10 aborda o prazer do estudante em estar em contato com a vida acadêmica e, novamente, os respondentes assinalaram, em grande maioria, as opções de maior concordância, sendo cerca de $72 \%$, com uma média de 7,8 .

O item 13 aborda o aspecto familiar, de forma a verificar se o fato das pessoas na família terem o título de doutor influencia o mestrando a buscar a realização do curso. Este foi o item com maior discordância dentre os 28 , sendo que cerca de $84 \%$ dos respondentes indicaram o número 1 na escala, e outros quase $8 \%$ indicaram o número 2 . Logo, a média para esse item é também a mais baixa dentre todos os itens do questionário. Esse resultado sugere que os respondentes não se sentem mais ou menos motivados para realizar um doutorado em decorrência da presença de doutores na família.

Com relação à continuidade dos estudos, tratada no item 22, verifica-se que grande parte dos mestrandos considera que a sequência dos estudos permitirá o aprendizado de coisas interessantes para o aluno, o que é refletido na mediana alta deste item. Também ligado à motivação intrínseca para saber, o item 2 se refere a satisfação em aprender coisas novas, e um fator que chama a atenção é o percentual de respondentes que assinalou a opção de maior concordância, cerca de $45 \%$. Além disso, este item é o que apresenta a média mais alta dentre todos os 28 . O estudo de Oliveira et al. (2010) também constatou altos níveis de correspondência com a motivação intrínseca para saber, assim como no estudo de Lopes et al. (2015).

Tabela 3 - Média e mediana da Escala de Motivação Acadêmica (EMA) aplicada na pesquisa.

\begin{tabular}{|c|c|c|c|c|}
\hline & Descrição & Motivação & Média & Mediana \\
\hline 1 & $\begin{array}{l}\text { Porque acredito que o título de doutor me proporcionará uma ocupação mais } \\
\text { bem remunerada no futuro. }\end{array}$ & Extrínseca & 8,01 & 9 \\
\hline 2 & Porque sinto satisfação e prazer enquanto aprendo coisas novas. & Intrínseca & 8,43 & 9 \\
\hline 3 & $\begin{array}{l}\text { Porque acho que um doutorado me preparará melhor para a carreira que } \\
\text { escolhi. }\end{array}$ & Extrínseca & 7,73 & 8 \\
\hline 4 & Porque gosto de ter contato com a universidade & Extrínseca & 7,81 & 8 \\
\hline 5 & $\begin{array}{l}\text { Acho que o doutorado seria uma perda de tempo porque não me traria } \\
\text { benefícios futuros. }\end{array}$ & Desmotivação & 1,86 & 1 \\
\hline 6 & Pelo prazer que sinto quando supero a mim mesmo nos estudos & Intrínseca & 7,52 & 8 \\
\hline 7 & Para provar a mim mesmo que sou capaz de completar o curso. & Extrínseca & 5,23 & 5 \\
\hline 8 & $\begin{array}{l}\text { Pelo prazer que sinto quando entro em contato com aquilo que eu nunca } \\
\text { tinha visto ou conhecido. }\end{array}$ & Intrínseca & 7,07 & 8 \\
\hline 9 & Porque o curso será um diferencial para eu atuar numa área de que eu gosto. & Extrínseca & 8,04 & 9 \\
\hline 10 & Porque, para mim, estar em contato com a vida acadêmica é um prazer. & Extrínseca & 7,80 & 8 \\
\hline 11 & $\begin{array}{l}\text { Já estive mais motivado a realizar um curso de doutorado; agora, entretanto, } \\
\text { eu me pergunto se isso me proporcionaria algum benefício real. }\end{array}$ & Desmotivação & 4,65 & 4 \\
\hline 12 & $\begin{array}{l}\text { Pelo prazer que sinto quando supero a mim mesmo em alguma de minhas } \\
\text { realizações pessoais. }\end{array}$ & Extrínseca & 7,08 & 8 \\
\hline 13 & $\begin{array}{l}\text { Porque na minha família muitas pessoas têm esse título e, por isso, sinto-me } \\
\text { na obrigação de alcançá-lo. }\end{array}$ & Extrínseca & 1,49 & 1 \\
\hline 14 & Porque me sinto importante quando sou bem-sucedido academicamente. & Intrínseca & 5,63 & 6 \\
\hline 15 & $\begin{array}{l}\text { Pelo prazer que tenho em ampliar meu conhecimento sobre assuntos que me } \\
\text { atraem. }\end{array}$ & Intrínseca & 7,83 & 9 \\
\hline 16 & Porque acredito que o doutorado me proporcionará prestígio social. & Intrínseca & 5,14 & 5 \\
\hline 17 & Porque o doutorado me ajudará na minha inserção profissional. & Extrínseca & 7,42 & 8 \\
\hline 18 & $\begin{array}{l}\text { Pelo prazer que tenho quando me envolvo em debates interessantes com } \\
\text { meus professores. }\end{array}$ & Intrínseca & 6,65 & 8 \\
\hline 19 & $\begin{array}{l}\text { Não consigo perceber o que me motivaria a ingressar em um doutorado e, } \\
\text { francamente, não me preocupo com isso. }\end{array}$ & Desmotivação & 2,50 & 1 \\
\hline 20 & $\begin{array}{l}\text { Pela satisfação que sinto quando estou no processo de realização de } \\
\text { atividades acadêmicas dificeis. }\end{array}$ & Intrínseca & 5,60 & 6 \\
\hline
\end{tabular}




\begin{tabular}{|c|c|c|c|c|}
\hline & Descrição & Motivação & Média & Mediana \\
\hline 21 & Para mostrar a mim mesmo que sou uma pessoa inteligente. & Extrínseca & 3,76 & 3 \\
\hline 22 & $\begin{array}{l}\text { Porque a continuação dos meus estudos permitirá que eu continue a } \\
\text { aprender sobre muitas coisas que me interessam. }\end{array}$ & Intrínseca & 7,44 & 8 \\
\hline 23 & $\begin{array}{l}\text { Porque eu creio que um doutorado aumentará minha competência } \\
\text { como profissional. }\end{array}$ & Intrínseca & 7,27 & 8 \\
\hline 24 & $\begin{array}{l}\text { Porque o doutorado me proporcionará entrar em contato com } \\
\text { assuntos estimulantes. }\end{array}$ & Intrínseca & 7,14 & 8 \\
\hline 25 & Nada me faria ingressar em um doutorado. & Desmotivação & 1,76 & 1 \\
\hline 26 & $\begin{array}{l}\text { Por que o doutorado me permitirá sentir uma satisfação pessoal na minha } \\
\text { busca por excelência na formação. }\end{array}$ & Intrínseca & 7,38 & 8 \\
\hline 27 & $\begin{array}{l}\text { Porque quero mostrar a mim mesmo que posso ter sucesso nos estudos e a } \\
\text { realização do doutorado seria a concretização disso. }\end{array}$ & Extrínseca & 5,06 & 5 \\
\hline 28 & $\begin{array}{l}\text { Só realizaria um doutorado caso fosse uma exigência do mercado de trabalho } \\
\text { para ascender profissionalmente. }\end{array}$ & Extrínseca & 2,76 & 1 \\
\hline
\end{tabular}

Fonte: Dados da pesquisa.

Outros dois itens que apresentaram alto percentual de respostas entre os de maior discordância são o 19 e 25 , que estão ligados à desmotivação ou ausência de motivação. Primeiramente, para o item 19, cerca de $64 \%$ dos respondentes assinalaram a opção 1 e outros $8 \%$ a opção 2, o que representa uma média de 2,5; e para o item 25 , cerca de $81 \%$ assinalaram a alternativa 1, o que mostra que a grande maioria dos mestrandos participantes da pesquisa se mostram motivados a buscar o título de doutor. Nos achados estudo de Lopes et al. (2015), também pode-se verificar que os respondentes demonstraram baixo nível de desmotivação.

No que diz respeito à aquisição de novos conhecimentos, os participantes da pesquisa se mostraram motivados em ingressarem no curso, com o intuito de obter novas experiências, o que revela que a realização do doutorado está também atrelada à busca pelo saber. $\mathrm{O}$ item 8 apresenta média de 7,07 (prazer em ter contato com algo novo e/ou desconhecido), o item 15 7,83 (ampliar o conhecimento com assuntos atrativos), e o item 24 obteve média de 7,14 (entrar em contato com assuntos estimulantes).

Outros quatro itens (3, 9, 17 e 23) abordaram o aspecto profissional e, de acordo com a percepção dos participantes da pesquisa, verifica-se que a realização de um curso de doutorado auxilia na inserção profissional, de forma a melhor preparar o acadêmico para o mercado de trabalho, representando um diferencial para a atuação na área. Destaque para o item 9, que obteve mediana igual a 9 e média 8,04, onde cerca de $70 \%$ dos alunos assinalaram as opções de maior concordância (8, 9 e 10). O último item do questionário, ligado à desmotivação ou ausência de motivação, corrobora com este argumento, pois cerca de $74 \%$ dos respondentes marcaram as opções de maior discordância (1, 2 e 3), o que possivelmente indica que os participantes da pesquisa não entrariam em um programa de doutorado se fosse uma exigência de mercado, e sim por vontade própria.

Um aspecto que merece destaque é o resultado apresentado no primeiro item, que retrata o aspecto financeiro após a obtenção do título de doutor, na qual a grande maioria dos respondentes se manteve a favor dessa afirmação, conforme evidenciado na figura 2 . Apenas cerca de $6 \%$ dos mestrandos assinalaram as opções de maior discordância (1, 2 e 3), sendo que a mediana para esse item é de 9 , o que denota a importância do doutorado para esse quesito, na percepção dos alunos. 
Figura 2: Respostas da primeira afirmativa do instrumento de pesquisa.

Porque acredito que o título de doutor me proporcionará uma ocupação mais bem remunerada no futuro. (209 respostas)

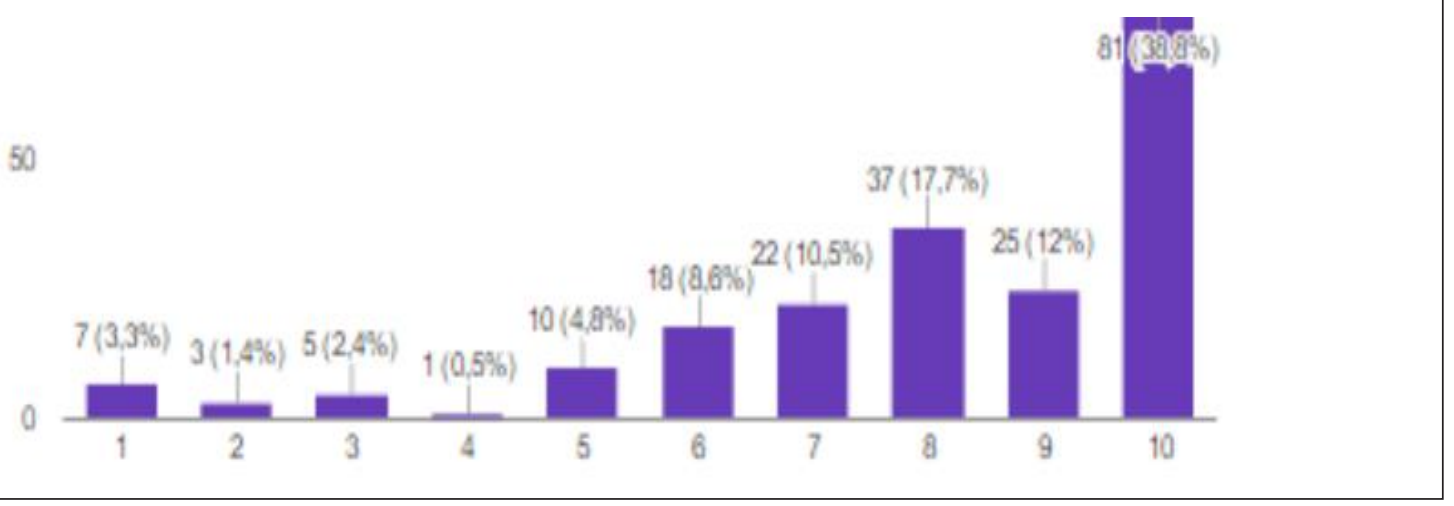

Fonte: Dados da pesquisa.

Além dos itens já citados, ressaltam-se também os itens 7 e 21, ligados à motivação extrínseca regulada por identificação. A maioria dos respondentes concentrou as respostas destas questões nas alternativas de maior discordância, o que reflete nas baixas medianas (respectivamente 5 e 3) e médias (respectivamente 5,23 e 3,76).

Tabela 4 - Teste Shapiro-Wilk.

\begin{tabular}{l|c|c|c|c|c}
\hline Variáveis & Obs & $\mathbf{W}$ & $\mathbf{V}$ & $\mathbf{z}$ & Prob $>\mathbf{z}$ \\
\hline Intrínseca para saber (a) & 209 & 0,87778 & 18,947 & 6,783 & 0,00000 \\
Intrínseca para realização (b) & 209 & 0,94049 & 9,225 & 5,124 & 0,00000 \\
Intrínseca para vivenciar estímulos (c) & 209 & 0,96110 & 6,030 & 4,143 & 0,00002 \\
Extrínseca regulação identificada (d) & 209 & 0,87321 & 19,656 & 6,868 & 0,00000 \\
Extrínseca regulação introjetada (e) & 209 & 0,98227 & 2,749 & 2,332 & 0,00985 \\
Extrínseca regulação externa (f) & 209 & 0,97911 & 3,239 & 2,710 & 0,00336 \\
Desmotivação (g) & 209 & 0,85228 & 22,899 & 7,220 & 0,00000 \\
\hline
\end{tabular}

Fonte: Dados da pesquisa.

Com o intuito de verificar se as variáveis dos tipos de motivação apresentam normalidade, foi realizado o teste Shapiro-Wilk, conforme demonstrado na tabela 4. Por meio deste teste, é possível verificar que as variáveis dos tipos de motivação não apresentam normalidade na distribuição dos dados, e então, foi utilizada a mediana para estabelecer os valores de cada variável motivacional, obtendo o valor final do IAM para os mestrandos em contabilidade participantes da pesquisa. A tabela 5 evidencia o comportamento correlacional entre as variáveis da escala EMA a partir da amostra analisada.

Tabela 5 - Correlação de Spearman entre as variáveis de motivação.

\begin{tabular}{l|c|c|c|c|c|c|c}
\hline Níveis de Motivação & (a) & (b) & (c) & (d) & (e) & (f) & (g) \\
\hline Intrínseca para saber (a) & 1,0000 & & & & & & \\
Intrínseca para realização (b) & 0,8178 & 1,0000 & & & & \\
Intrínseca para vivenciar estímulos (c) & 0,6980 & 0,7824 & 1,0000 & & & \\
Extrínseca regulação identificada (d) & 0,7721 & 0,7866 & 0,6342 & 1,0000 & & \\
Extrínseca regulação introjetada (e) & 0,5305 & 0,6643 & 0,6437 & 0,4069 & 1,0000 & & \\
Extrínseca regulação externa (f) & 0,0076 & 0,1914 & 0,2562 & 0,2320 & 0,1798 & 1,0000 \\
Desmotivação (g) & $-0,5614$ & $-0,5432$ & $-0,4454$ & $-0,6450$ & $-0,1788$ & $-0,1614$ & 1,0000 \\
\hline
\end{tabular}

Fonte: Dados da pesquisa. 
Os níveis correlacionais das variáveis da escala EMA, de acordo com as perguntas utilizadas para mensurar a motivação, demonstram valores correlacionais altos para todas variáveis, exceto para a variável motivação extrínseca por controle externo. Para as categorias de motivação intrínseca, o resultado indica que as variáveis ( $a$, b e c) apresentam níveis de correlação alto entre si, e também para a motivação extrínseca regulada por identificação (d), e para as demais uma baixa correlação, principalmente para a motivação extrínseca por regulação externa (f).

Conforme descrito na metodologia, o IAM pode variar de -108 a +108 , e quanto mais pontos positivos obtidos simboliza que o aluno tem mais motivação intrínseca. Por outro lado, quanto mais pontos negativos, mais motivado extrinsecamente ou desmotivado o aluno está. Para tanto, foi utilizada a fórmula desenvolvida por Sobral (2008), e já utilizada também no estudo de Durso et al. (2016), que estudou a motivação dos alunos de graduação em Ciências Contábeis e Ciências Econômicas a realizarem um mestrado acadêmico.

Tabela 6 - Índices de Autodeterminação da Motivação (IAM).

Tipos de Motivação

\begin{tabular}{l|l|l|l|l|l|l|l|} 
(a) & (b) & (c) & (d) & (e) & (f) & (g) & IAM \\
33 & 29 & 26 & 34 & 21 & 20 & 8 & 56 \\
\hline
\end{tabular}

Fonte: Dados da pesquisa.

A partir da Tabela 6, o valor da mediana dos 209 alunos pesquisados é de 56 pontos, demonstrando que os valores de motivações intrínsecas são maiores que os valores de motivações extrínsecas e desmotivação. $\mathrm{O}$ valor mais significativo é da motivação extrínseca por regulação identificada, o que significa que o mestrando faria o doutorado por que é algo importante para si mesmo, especialmente quando ele internaliza uma escolha. A partir dos dados, verifica-se que os mestrandos em Ciências Contábeis são mais motivados intrinsecamente a fazer doutorado, por satisfação, prazer de realizar uma tarefa e aprender.

Em seguida, a Tabela 7 apresenta a correlação entre cada uma das variáveis dos dados demográficos analisadas pelo estudo, aos tipos de motivação e o Índice de Autodeterminação da Motivação (IAM).

Tabela 7 - Correlação dos dados demográficos com Índice de Autodeterminação da Motivação (IAM).

\begin{tabular}{c|c|c|c|c|c|c|c|c}
\hline Variáveis & $(\mathbf{a})$ & $\mathbf{( b )}$ & $\mathbf{( c )}$ & $\mathbf{( d )}$ & $\mathbf{( e )}$ & $\mathbf{( f )}$ & $\mathbf{( g )}$ & IAM \\
\hline Gênero & 0,1784 & 0,1851 & 0,1134 & 0,2506 & 0,1205 & 0,2095 & $-0,1972$ & 0,1953 \\
Idade & 0,0794 & 0,0532 & 0,0083 & 0,0915 & $-0,0579$ & $-0,1349$ & $-0,0933$ & 0,1218 \\
Estado Civil & 0,0626 & 0,1201 & 0,1330 & 0,0911 & 0,0811 & $-0,1003$ & $-0,0810$ & 0,1396 \\
Bolsa & $-0,0178$ & 0,0285 & 0,0347 & $-0,0673$ & 0,0333 & $-0,0773$ & 0,0327 & $-0,0106$ \\
Vínculo Empregatício & 0,0684 & 0,0262 & $-0,0024$ & 0,0857 & $-0,0045$ & 0,0918 & $-0,1106$ & 0,0732 \\
\hline
\end{tabular}

Fonte: Dados da pesquisa.

Para verificar a correlação foi utilizado o coeficiente de correlação de postos de Spearman, devido aos dados não atenderam à normalidade. De maneira geral, é possível perceber que os índices de correlação demonstrados para as variáveis da pesquisa foram baixos, demonstrando assim que não há relação significante entre as variáveis gênero, idade, estado civil, se é bolsista, ou se possui vínculo empregatício, com as variáveis motivacionais.

\section{CONSIDERAÇÕES FINAIS}

O objetivo do estudo é verificar o nível motivacional dos mestrandos em Ciências Contábeis com relação ao ingresso em um programa de doutorado, com o intuito de responder a seguinte questão de pesquisa: Qual o nível de motivação dos mestrandos dos Cursos de Ciências Contábeis a ingressarem em um programa de doutorado? Por meio da utilização da Escala de Motivação Acadêmica (EMA), desenvolvida a partir da Teoria da Autodeterminação por Vallerand et al. (1992), o estudo analisa as 209 respostas de mestrandos em Ciências Contábeis de todo o Brasil.

Verifica-se que o estudo atendeu ao objetivo proposto e, a partir dos achados, observa-se que, em geral, a realização de um doutorado traz benefícios futuros ao estudante, representando um diferencial na carreira acadêmica e profissional. Os mestrandos em Ciências Contábeis apresentaram alto nível de motivação para ingressar em um programa de doutorado e manter contato com o meio acadêmico. Os respondentes consideraram que o título de doutor representa um diferencial na carreira acadêmica e profissional, trazendo também benefícios financeiros.

Pode-se considerar que o instrumento utilizado pela pesquisa é satisfatório em mensurar os fatores que motivam os mestrandos em Ciências Contábeis a realizar um doutorado acadêmico, tendo em vista que já é consolidado no âmbito acadêmico, em razão da grande aplicabilidade em pesquisas relacionadas à motivação de estudantes. Em comparação 
aos graduandos em Ciências Contábeis, que fizeram parte da análise do trabalho de Durso et al. (2016), verifica-se, a partir do Índice de Autodeterminação da Motivação elaborado por Sobral (2008), que os mestrandos da amostra, em geral, são mais motivados a realizarem um doutorado do que os graduandos da amostra a ingressarem em um programa de mestrado. Segundo os autores, os estudantes de Ciências Contábeis possuem um perfil voltado para o mercado de trabalho e acabam adiando o objetivo de obter um grau acadêmico mais elevado, e, inseridos no mercado de trabalho, consequentemente acabam enfrentando barreiras que os impedem de realizar um mestrado acadêmico.

A partir dos achados da pesquisa, verifica-se que os mestrandos em Ciências Contábeis demonstram entusiasmo em manter contato com o ambiente acadêmico, e que o ingresso em um programa de doutorado pode proporcionar a sequência da carreira acadêmica, representando a junção do retorno financeiro com o prazer e satisfação de estudar e realizar novas tarefas, de modo a manter contato com o ambiente e assuntos de interesse.

Com base nos resultados do estudo, coordenadores de programas de mestrado e doutorado, professores, alunos, diretores, e demais envolvidos, possuem dados que podem auxiliar no desenvolvimento e crescimento dos programas de pós-graduação stricto sensu em Ciências Contábeis no Brasil, no que diz respeito às normas dos programas, projetos de pesquisa e programas de incentivo aos alunos (maior oferta de bolsas de estudo, ou ainda, melhor distribuição das mesmas).

Destaca-se como limitação do estudo o fato de que os achados se aplicam somente aos mestrandos que fizeram parte da pesquisa, conforme evidenciado na tabela 2. Portanto, os resultados são específicos para esta amostra, não podendo ser generalizados para os alunos de outros cursos. Assim, recomenda-se para pesquisas futuras analisar a motivação dos mestrandos em Administração e Ciências Econômicas, de forma a comparar com os achados dessa pesquisa.

\section{REFERÊNCIAS}

Biondi, E. A., Varade, W. S., Garfunkel, L. C., Lynn, J. F., Craiq, M. S., Cellini, M. M., Shone, L. P., Harris, J. P., Badwin. C. D. (2015). Discordance between resident and faculty perceptions of resident autonomy: can self-determination theory help interpret differences and guide strategies for bridging the divide? Academic Medicine, 90(4), 1-10.

Blundell, R., Dearden, L., Meghir, C., Sianesi, B. (1999). Human Capital Investment: The Returns from Education and Training to the Individual, the Firm and the Economy. Fiscal Studies, 20(1), 1-23.

Brasil. CESu/CFE. Parecer 977 de 03 de dezembro de 1965 (1965). Dispõe sobre a definição da natureza e objetivos dos cursos de pós-graduação no Brasil. Recuperado em 24 de agosto, 2016, de http://www.portal.mec.gov.br/cne/arquivos/pdf/2007/parecer\%20 cfe\%20977-1965.pdf.

Capes. Coordenação de Aperfeiçoamento de Pessoal de Nível Superior (CAPES). Mestrados/Doutorados reconhecidos. Recuperado em 25 de agosto, 2016, de: http://www.capes.gov.br.

Deci, E. L., \& Ryan, R. M. (1985). Intrinsic motivation and self-determination in human behavior, New York, Plenum.

Deci, E. L., \& Ryan, R. M. (2000). Intrinsic and Extrinsic Motivations: Classic Definitions and New Directions. Contemporary Educational Psychology, 25, 54-67.

Deci, E. L., \& Ryan, R. M. (2008). Self-determination theory: a macrotheory of human motivation, development, and health. Canadian Psychology, 49(3), 182-185.

Deci, E. L., Ryan, R. M., Vallerand, R. J., \& Pelletier, L. G. (1991) Motivation and Education: The Self-Determination Perspective. Educational Psychologist, 26(4), 325-346.

Deci, E. L. Ryan, R. M., Kuhl, J. (1997). Nature and autonomy: Organizational view of social and neurobiological aspects of selfregulation in behavior and development. Development and Psychopathology, 9, 701-728.

Durso, S. de. O., Cunha, J. V. A. da., Neves, P. A., \& Teixeira, J. D. V. (2016). Fatores motivacionais para o mestrado acadêmico: uma comparação entre alunos de Ciências Contábeis e Ciências Econômicas à luz da Teoria da Autodeterminação. Revista Contabilidade e Finanças, 27(71), 243-258.

Gagné, M., \& Deci, E. L. (2005). Self-determination theory and work motivation. Journal of Organizational Behavior, 26, 331-362.

Guimarães, S. E. R., \& Bzuneck, J. A. (2008). Propriedades psicométricas de um instrumento para avaliação da motivação de universitários. Ciências \& Cognição, 3(1), 101-113.

Guimarães, S. E. R., Bzuneck, A. J., \& Sanches, S. F. (2002). Psicologia educacional nos cursos de licenciatura: a motivação dos estudantes. Psicologia Escolar e Educacional, 6(1), 11-19.

Leal, E. A., Miranda, G. J., \& Carmo, C. R. S. (2013). Teoria da Autodeterminação: uma análise da motivação dos estudantes do curso de Ciências Contábeis. Revista Contabilidade \& Finanças, 24(62), 162- 173. 217- 272.

Lima, R. (1980). Mercado de trabalho: o capital humano e a teoria da segmentação. Pesquisa e Planejamento Econômico, 10(1),

Lopes, L. M. S., Pinheiro, F. M. G., Silva, A. C. R. da., \& Abreu, E. S. de. (2015). Aspectos da motivação intrínseca e extrínseca: uma análise com discentes de Ciências Contábeis da Bahia na perspectiva da Teoria da Autodeterminação, Revista de Gestão, Finanças e Contabilidade, 5(1), 21-39.

Martins, O. S., \& Monte, P. A. do. (2009). Mestres em Ciências Contábeis: uma análise sob a ótica da teoria do capital humano. Revista de Educação e Pesquisa em Contabilidade, 3(2), 1-22. 
Oliveira, P. A., Theóphilo, C. R., Batista, I. V. C., \& Soares (2010). Motivação sob a perspectiva da Teoria da Autodeterminação: um estudo da motivação de alunos do curso de Ciências Contábeis da Universidade Estadual de Montes Claros. Anais do Congresso USP de Controladoria e Contabilidade, Universidade de São Paulo, São Paulo, SP, Brasil, 10.

Richardson, Roberto Jarry. (2012). Pesquisa social: métodos e técnicas. 3.ed. São Paulo: Atlas.

Ryan, R. M., Williams, G. C., Patrick, H., Deci, E. L. (2009). Self-determination theory and physical activity: the dynamics of motivation in development and wellness. Hellenic Journal of Psychology, 6(1), 107-124.

Silva, A. C. R. (2010). Metodologia da pesquisa aplicada à contabilidade. 3. ed. São Paulo: Atlas.

Sobral, D. T. (2003). Motivação do Aprendiz de Medicina: Uso da Escala de Motivação Acadêmica. Psicologia: Teoria e Pesquisa, 19(1), 25-31.

Sobral, D. T. (2008). Autodeterminação da motivação em alunos de medicina: relação com motivos de escolha da opção e intenção de adesão ao curso. Revista Brasileira de Educação Médica, 32(1), 56-65.

Vallerand, R. J., Blains, M. R., Brière, N. M., Pellettier, L. G. (1989). Construction et validation de I'echelle de motivation en education (EME). Revue Européenne de Psychologie Appliquée, 49(3), 261-274.

Vallerand, R. J., Pelletier, L. G., Blais, M. R., Brière, N. M., Senécal, C., \& Vallières, E. F. (1992). The academic motivation scale: a measure of intrinsic, extrinsic, and amotivation in education. Educational and Psychological Measurement, 52(4), 1003-1017. 